\title{
Decreased expression of apoptosis-inducing factor in renal cell carcinoma is associated with poor prognosis and reduced postoperative survival
}

\author{
ZHAOXING WANG $^{1 *}$, CHAO YUAN $^{2,3^{*}}$, YUAN HUANG $^{4}$, ZHENXIANG LIU $^{1}$, \\ $\mathrm{XIN} \mathrm{YU}^{2,3}, \mathrm{CAI} \mathrm{LV}^{1}$ and ZHENHONG SU $\mathrm{SU}^{2,3,5}$
}

${ }^{1}$ Department of Urology, Affiliated Haikou Hospital of Xiangya Medical School of Central South University, Haikou,

Hainan 570208; ${ }^{2}$ Hubei Key Laboratory for Kidney Disease Pathogenesis and Intervention, Hubei Polytechnic

University School of Medicine; ${ }^{3}$ Clinical Laboratory, Huangshi Central Hospital of The Edong Healthcare Group, Huangshi, Hubei 435000; ${ }^{4}$ Department of Neurology, Affiliated Haikou Hospital of Xiangya, Medical School of Central South University, Haikou, Hainan 570208; ${ }^{5}$ Clinical Laboratory, Huangshi Fourth People Hospital, Huangshi, Hubei 435000, P.R. China

Received June 18, 2018; Accepted April 26, 2019

DOI: $10.3892 / \mathrm{ol} .2019 .10630$

\begin{abstract}
Apoptosis-inducing factor (AIF) serves a crucial role in cell death and is involved in several types of cancer, including kidney cancer. The present study aimed to explore the association between AIF expression and patient survival based on tumor grades. AIF expression in 96 patients with renal cell carcinoma (RCC) was investigated using immunohistochemistry. Negative AIF expression was determined in 80 patients $(83.3 \%)$. mRNA expression of AIF was analyzed in RCC and adjacent tissue samples from 15 patients. AIF mRNA expression in RCC tissues were significantly lower compared with that in adjacent tissues. Analysis of histopathological grades revealed that AIF expression was negatively associated with RCC grade, with AIF expression in Grade II tumors being lower than Grade I types, but higher than Grade III. Finally, 68 patients were followed up for 6-118 months, and it was revealed that the overall postoperative survival rate of
\end{abstract}

Correspondence to: Dr Zhenhong Su, Hubei Key Laboratory for Kidney Disease Pathogenesis and Intervention, Hubei Polytechnic University School of Medicine, 16 Guilin North Road, Huangshi, Hubei 435000, P.R. China

E-mail: szh7977@163.com

Dr Cai Lv, Department of Urology, Affiliated Haikou Hospital of Xiangya Medical School of Central South University, 43 Renming Road, Haikou, Hainan 570208, P.R. China

E-mail: 1vcai815@163.com

*Contributed equally

Abbreviations: AIF, apoptosis-inducing factor; RCC, renal cell carcinoma; OS, overall postoperative survival; RT-qPCR, reverse transcription quantitative polymerase chain reaction

Key words: RCC, immunohistochemistry, diagnostic marker, postoperative survival, AIF patients with negative AIF expression was significantly lower compared with those those with positive AIF expression. These results suggest that decreased AIF expression could be associated with worsening RCC grade. Therefore, reduced AIF expression may potentially help diagnose RCC and distinguish tumor grades.

\section{Introduction}

Apoptosis-inducing factor (AIF) is a mitochondrial oxidoreductase that plays a role in oxidative phosphorylation and redox control in normal cells (1). AIF was originally cloned and identified as a mitochondrial effector of caspase-independent apoptotic cell death (2). Programmed cell death is a fundamental requirement for embryogenesis, organ metamorphosis and tissue homeostasis (3). In mammals, the release of mitochondrial cytochrome $c$ results in the cytosolic assembly of the apoptosome, a caspase activation complex involving apoptotic protease-activating factor 1 (APAF1) and caspase-9, which induce apoptosis (4). However, there are mitochondria-regulated cell-death pathways that are independent of APAF1/caspase-9. Similar to cytochrome $c$, under normal conditions, AIF is usually confined to the mitochondrial intermembrane space and released in response to death stimuli, and following the induction of apoptosis, AIF is translocated to the nucleus, where it influences chromosome condensation and fragmentation $(1,5)$. In addition, AIF can induce mitochondria to release the apoptogenic proteins including cytochrome $c$ and caspase-9 (1). Joza et al (3) showed that the genetic inactivation of AIF renders embryonic stem cells resistant to cell death after serum deprivation. Moreover, AIF is essential for programmed cell death during the cavitation of embryoid bodies, which is the very first wave of cell death indispensable for mouse morphogenesis (3). AIF-dependent cell death exhibits structural features similar to those of apoptosis and can be genetically uncoupled from APAF1 and caspase-9 expression (5). Joza et al (3) concluded that their data provide genetic evidence for a 
caspase-independent pathway of programmed cell death that controls early morphogenesis.

In addition to its role in cell death, Shen et al (6) reported that AIF could influence tumor invasion and metastasis by physically interacting with and protecting phosphatase and tensin homolog on chromosome ten (PTEN) from oxidation. PTEN is a tumor suppressor that is susceptible to oxidation-mediated inactivation (7-10). A study by Tsai et al (11) demonstrated that an asthma medication, montelukast, induced lung cancer cell death via the nuclear translocation of AIF. Ohyama et al (12) observed a similar phenomenon where phosphatidylinositol derivatives induced caspase-independent apoptosis in gastric cancer cells through the accumulation of AIF and AIF-homologous mitochondrion-associated inducer of death in cancer cell nuclei. These findings indicated that AIF is involved in cell homeostasis and tumor development.

The AIF gene encodes a mitochondrial flavin adenine dinucleotide-dependent oxidoreductase that serves a role in oxidative phosphorylation and redox control in healthy cells by triggering chromatin condensation and DNA fragmentation (2). Xu et al (13) reported that owing to AIF deletion and the methylation of its promoter, AIF was downregulated in a majority of renal cell carcinomas (RCC) and that AIF overexpression in RCC cell lines could considerably induce apoptosis. Further investigations by $\mathrm{Xu}$ et al (13) demonstrated that AIF interacts with STK3, a known apoptosis regulator, and enhances its phosphorylation at Thr180. Despite these previous findings of the role of AIF in cancer, further studies are warranted to investigate the association between AIF expression and RCC grade.

$\mathrm{RCC}$ is a high-risk and high-mortality kidney cancer originating in the lining of the proximal convoluted tubules, and accounts for $2-3 \%$ of human cancers worldwide $(14,15)$. In China, RCC is the second most frequent genitourinary malignant cancer, demonstrating a steady increase in frequency (16) Since 2005, following a clearer understanding of the molecular mechanisms underlying RCCs, targeted therapies with small molecules have replaced cytokines in treating metastatic RCC. The survival time has increased from 10-12 months to 20-22 months $(17,18)$. Considering the mortality rate associated with RCC and the challenging therapy, the identification of novel molecular markers for kidney cancer is vital for decreasing mortality and enhancing quality of life for patients. In addition, the identification of novel markers can facilitate the evaluation of individual risk, prognosis and help to predict the effects of therapy and advocacy for personalized treatment (19).

Although AIF was reported to decrease apoptosis in press kidney cells, the expression of AIF in RCC and the association between AIF expression and prognosis of RCC required further study. In the present study, AIF expression was investigated in RCC using immunohistochemistry (IHC), and the association between AIF expression and the prognosis of RCC was evaluated.

\section{Materials and methods}

Patients and tissue samples. In total, 96 pairs (78 of clear cell carcinoma, 13 of papillary carcinoma and 5 of other tissue types) of RCC and adjacent tissue specimens and a second set of 15 pairs of RCC and adjacent fresh tissue were collected from patients who attended the Haikou Municipal Hospital, which is affiliated to the Xiangya School of Medicine of the Central South University (Haikou, China). The inclusion criteria were patients undergoing radical nephrectomy or nephrosparing surgery. The exclusion criteria were patients receiving chemotherapy or targeted drug therapy and patients with distant RCC metastasis (T4) that did not undergo surgical treatment patients with grade IV RCC were excluded due to the very small number of patients, which was not suitable for statistical analysis. The 96 pairs of RCC and adjacent tissue specimens were collected by surgical removal between June 2004 and June 2014 from 63 males and 33 females aged 25-82 (mean, 64) years. All specimens were fixed in $10 \%$ formalin at $4^{\circ} \mathrm{C}$ for $12 \mathrm{~h}$ within $1 \mathrm{~h}$ of surgery, and then embedded in paraffin. Among these, 68 patients were followed up for 6-118 months (mean follow-up time, 47 months). None of the patients received chemotherapy or any other medications prior to surgery. The present study was approved by the Ethics Committee of Haikou Municipal Hospital, which is affiliated to the Xiangya School of Medicine of the Central South University. Written informed consent was obtained from all patients.

IHC. Paraffin-embedded tissue sections were dewaxed, hydrated and placed in EDTA antigen-repair solution $(\mathrm{pH} 9.0)$ at $95^{\circ} \mathrm{C}$ for $10 \mathrm{~min}$ for antigen repair. Endogenous peroxidase was blocked using $3 \% \mathrm{H}_{2} \mathrm{O}_{2}$ for $10 \mathrm{~min}$ at room temperature. Subsequently, anti-human AIF antibody (1:100 in PBS; cat. no. 200-401-985; Rockland Immunochemicals Inc.) was added, and the tissue sections were incubated at $4^{\circ} \mathrm{C}$ in a humidity chamber overnight. The sections were then treated with horseradish peroxidase-conjugated secondary antibodies (1:200 in PBS; cat. no. GB23303; Servicebio) at $37^{\circ} \mathrm{C}$ for $30 \mathrm{~min}$ and diaminobenzidine reagent according to the manufacturer's instructions (DAB Horseradish Peroxidase Color Development Kit; cat. no. P0203; Beyotime Institute of Biotechnology). For the negative control group, PBS buffer without primary antibody was used. The results of the IHC were imaged at 20x and 40x on an Olympus Corporation light microscope and subjected to a double-blind analysis by two pathologists. Each specimen was randomized to count the number of positive cells in five high-power fields and was scored based on the average percentage of positive cells: $\leq 5 \%, 0$ points; $6-25 \%, 1$ point; $26-50 \%, 2$ points; $51-75 \%, 3$ points; and $>75 \%, 4$ points. In addition, the specimens were scored according to the intensity of color: No coloring, 0 points; light yellow, 1 point; brown, 2 points; light brown, 3 points; and dark brown, 4 points. Finally, the two scores were added and categorized as follows: 0-2, negative; 3-5, weak positive; and 6-8, strong positive. To facilitate statistical analysis, a score of $\geq 3$ points was classified as positive. To quantify AIF expression in Figs. 1B and 3B, Image Pro plus version 6.0 software (Media Cybernetics, Inc.) was used to quantify the intensity of staining.

Reverse transcription quantitative polymerase chain reaction (RT-qPCR). A second set of 15 pairs of RCC and adjacent fresh tissue specimens were collected by surgical removal 

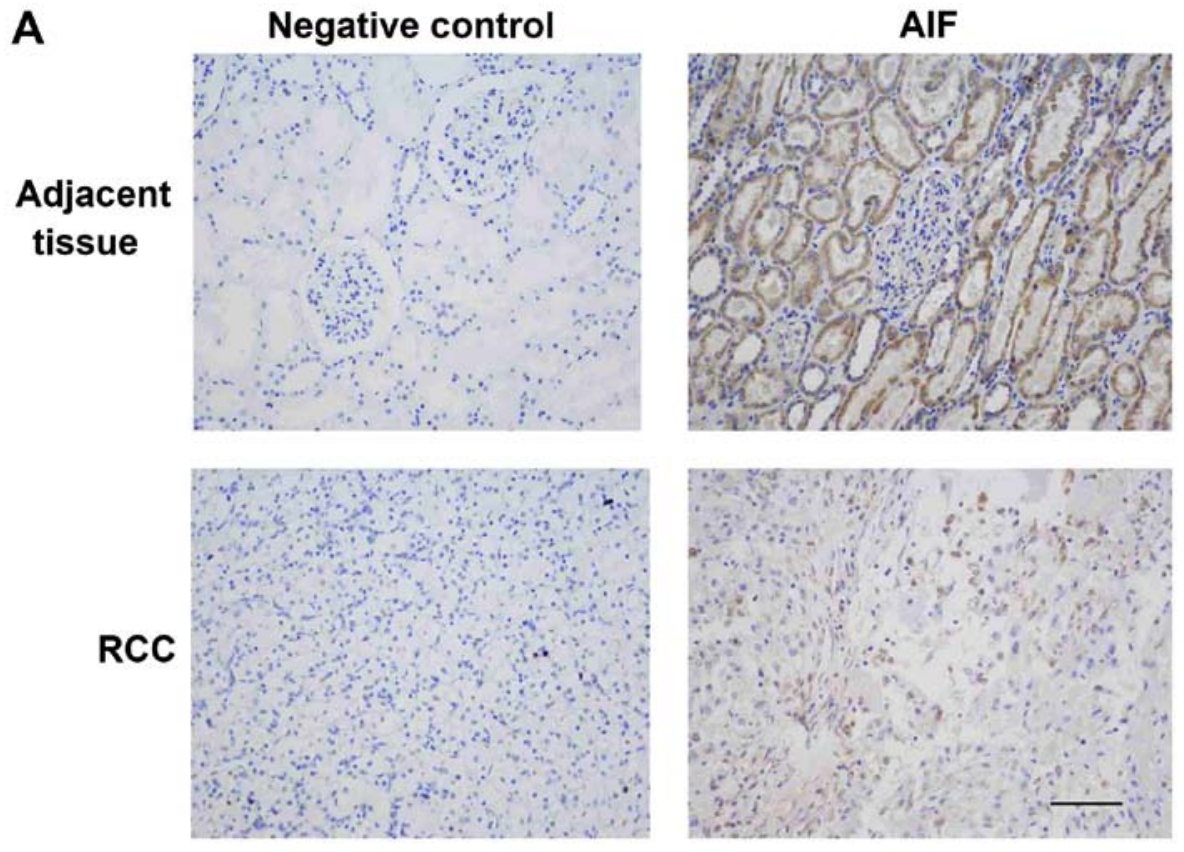

B

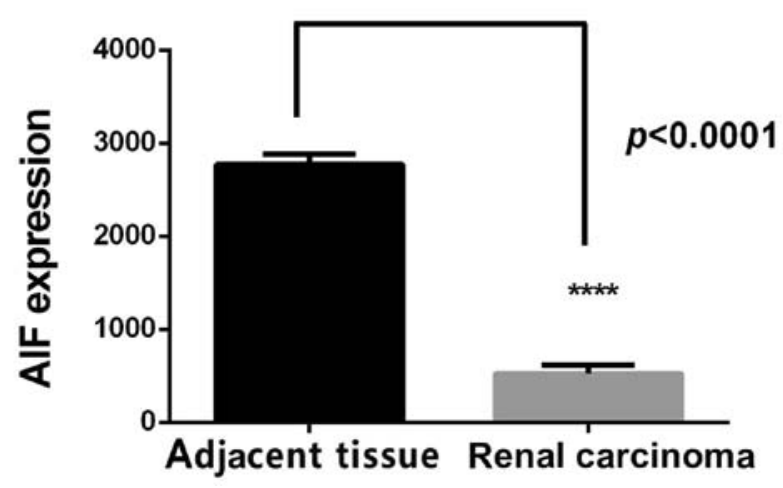

Figure 1. AIF expression in RCC and adjacent normal tissues. (A) IHC staining of AIF expression in RCC and adjacent tissues. Strong staining of AIF was observed in normal kidney sections compared with weak staining in the adjacent tissues. (B) Quantification of AIF staining in IHC images of RCC and adjacent normal tissues. AIF expression was significantly decreased in RCC tissues. ${ }^{* * * * *} \mathrm{P}<0.0001, \mathrm{n}=96$. Scale bar, $200 \mu \mathrm{m}$. AIF, apoptosis-inducing factor; RCC, renal cell carcinoma; IHC, immunohistochemistry.

between April 2015 and April 2017 including 11 males and 4 females aged 25-82 (mean, 63 \pm 8.7 ) years. Total RNA from 15 pairs of RCC and adjacent tissues, which were stored in liquid nitrogen, was extracted using TRIzol ${ }^{\circledR}$ (Invitrogen; Thermo Fisher Scientific, Inc.) according to the manufacturer's protocol. Briefly, $2 \mu \mathrm{g}$ of RNA was added to a solution of random primers ( $2 \mathrm{ml}$; Beijing ComWin Biotech Co., Ltd.) and water to a final volume of $15 \mu \mathrm{l}$. The mix was incubated at $70^{\circ} \mathrm{C}$ for $10 \mathrm{~min}$, and then placed on ice immediately for $5 \mathrm{~min}$. Subsequently dNTPs $(0.25 \mu \mathrm{l}$; Takara Bio, Inc.), M-MLV Reverse Transcriptase (1 ml; Promega Corporation) and RNase inhibitor $(0.5 \mathrm{ml}$; Promega Corporation) were added to the $15-\mu 1 \mathrm{mix}$. Finally, water was added to a final volume of $25 \mu \mathrm{l}$ and the solution was incubated at $37^{\circ} \mathrm{C}$ for $1 \mathrm{~h}$ to synthesize cDNA. qPCR was performed using $10 \mu \mathrm{l}$ SYBR $^{\circledR}$ Green PCR Master mix (Roche Diagnostics), with specific forward and reverse primers and cDNA on an ABI QuantStudio version 5 (Applied Biosystems; Thermo Fisher Scientific, Inc.). The thermocycling conditions for the qPCR were: $95^{\circ} \mathrm{C}$ For $10 \mathrm{~min}$ followed by 40 cycles of $95^{\circ} \mathrm{C}$ for $15 \mathrm{sec}$ and $60^{\circ} \mathrm{C}$ for $30 \mathrm{sec}$. The following primers were obtained from Tsingke Biological Technology: AIF forward, 5'-AAG AAGTGGTCTGACCTCAAGA-3' and reverse, 5'-AGGTTG CAGATACGTTGTTGC-3'; and GAPDH forward, 5'-ATG GGGAAGGTGAAGGTCG-3' and reverse, 5'-GGGGTC ATTGATGGCAACAATA-3'. GAPDH was used as the reference gene. The results were quantified using the $2^{-\Delta \Delta C q}$ as described previously (20).

Immunofluorescence assay. The 96 pairs of RCC and adjacent tissues (grades I, II and III) were incubated with a primary AIF monoclonal antibody (1:50; cat. no. MA5-15880; Invitrogen; Thermo Fisher Scientific, Inc.). The tissues were incubated with a voltage-dependent anion-selective channel 1 (VDAC1) rabbit polyclonal antibody (1:50; cat. no. 10866-1-AP; Proteintech Group, Inc.) at $4^{\circ} \mathrm{C}$ overnight, which served as a mitochondrial marker. The tissues were subsequently incubated at $37^{\circ} \mathrm{C}$ for $1 \mathrm{~h}$ with an Alexa Fluor 488 goat anti-mouse immunoglobulin $\mathrm{G}(\mathrm{IgG})(\mathrm{H}+\mathrm{L})$ antibody (1:20,000; cat. no. A32723; Thermo Fisher Scientific, Inc.) and an Alexa Fluor 555 goat anti-rabbit $\operatorname{IgG}(\mathrm{H}+\mathrm{L})$ antibody (1:500; cat. no. A21428; Thermo Fisher Scientific, Inc.). Nuclei were counterstained using DAPI 
Table I. Association of AIF expression in renal cell carcinoma and adjacent normal tissue.

\begin{tabular}{lcccc}
\hline & \multicolumn{2}{c}{ AIF expression } & & \\
\cline { 2 - 3 } Tissue type & Positive, $\mathrm{n}$ & Negative, $\mathrm{n}$ & $\chi^{2}$ value & P-value \\
\hline $\begin{array}{l}\text { Renal cell } \\
\text { carcinoma }\end{array}$ & 16 & 80 & 96.5 & $<0.001$ \\
Adjacent & 84 & 12 & & \\
\hline
\end{tabular}

AIF, apoptosis-inducing factor.

(Invitrogen; Thermo Fisher Scientific, Inc.) at room temperature for 10 min, and images were obtained using a FV1000 confocal microscope at $60 \mathrm{x}$ magnification. The signal values of AIF (green), VDAC1 (red), Merge (yellow) and DAPI (blue) were counted from 6 randomly selected with Image Pro Plus6.0 for quantification. The ratio of Merge/AIF was the percentage of mitochondria, and the rest were considered nuclei.

Statistical analysis. SPSS version 17.0.1 (SPSS, Inc.) and GraphPad Prism 6 (GraphPad Software, Inc.) were used for statistical analyses. The differences between two groups were compared using a paired Student's t-test, and $\geq 3$ groups were compared using one-way ANOVA with a Tukey's post hoc test. Survival rates were compared using the Kaplan-Meier method and a log rank test was used to compare the survival curves of patients in the two groups. The association between clinicopathological features and AIF expression was analyzed using a Pearson's $\chi^{2}$ test. $\mathrm{P}<0.05$ was considered to indicate a statistically significant difference.

\section{Results}

AIF staining is decreased in RCC tissues. To investigate the role of AIF in RCC, 96 pairs of RCC and adjacent normal tissues were collected and AIF expression was determined using IHC. As shown in Fig. 1A, AIF was highly expressed in adjacent normal tissues, primarily in renal tubular epithelial cells with less expression in glomerular membrane cells. AIF expression in RCC tissue was low. Quantification of staining confirmed that AIF expression was significantly lower in RCC tissues compared with normal renal tissue (Fig. 1B and Table I).

AIF mRNA expression is decreased in RCC tissues. To further compare AIF expression in RCC and adjacent normal tissues, AIF mRNA expression was determined in 15 pairs of RCC and adjacent tissues. The results revealed that AIF expression was significantly decreased in RCC tissues compared with that in adjacent normal tissues (Fig. 2).

AIF expression decreases with RCC progression. IHC findings demonstrated that reduced AIF expression was associated with increasing tumor grade. As shown in Table II, $87.5 \%$ of the adjacent normal tissue exhibited positive AIF expression. Conversely, 27.8, 16.7 and 5.6\% of Grades I, II and III
Table II. Apoptosis-inducing factor expression in renal cell carcinoma grades I, II and III and adjacent normal tissue.

\begin{tabular}{lccc}
\hline Group & Samples, $\mathrm{n}$ & Positive, $\%$ & Negative, \% \\
\hline Normal tissue & 96 & 87.5 & 12.5 \\
RCC (total) & 96 & 16.7 & 83.3 \\
Grade I & 36 & 27.8 & 72.2 \\
Grade II & 24 & 16.7 & 83.3 \\
Grade III & 36 & 5.6 & 94.4 \\
\hline
\end{tabular}

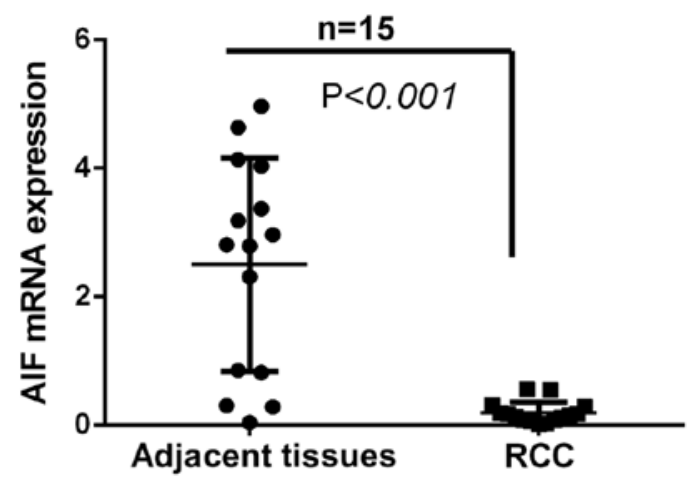

Figure 2. AIF mRNA expression in RCC and adjacent normal tissues. Total RNA extracted from 15 pairs of RCC and adjacent normal tissues was used for reverse transcription quantitative polymerase chain reaction. AIF expression in RCC tissues was significantly lower compared with that in adjacent normal tissues. $(n=15)$. AIF, apoptosis-inducing factor; RCC, renal cell carcinoma.

RCC samples exhibited positive AIF expression, respectively (Table II). The results revealed that AIF expression was associated with RCC progression (Table II). Quantification of AIF expression based on IHC demonstrated that AIF expression was significantly decreased in Grade I, II and III RCC compared with that in adjacent normal tissues (Fig. 3). Additionally, AIF expression in Group III was significantly lower than that in Group II, which was also lower than that in Group I. These results suggest that AIF expression is negatively associated with RCC grade. Thus, AIF downregulation may be a useful biomarker for diagnosing RCC and distinguishing tumor grades.

Reportedly, translocation of AIF from the mitochondrial intermembrane space in normal embryonic stem cells to the nucleus induces apoptosis (3). To examine the subcellular localization of AIF in RCCs, immunofluorescence staining was performed. As presented in Fig. 4A and B, AIF was found to be downregulated in RCC tissues according to tumor grade. Additionally, it was observed that AIF was primarily present in mitochondria (62.25\%) in adjacent tissues, and less AIF was present in the nuclei (37.75\%). In RCC tissues, more AIF was present in nuclei compared with mitochondria (Grade I, 39.53\%; Grade II, 57.71\% and Grade III, 83.61\%) (Fig. 4A and C). These results suggest that AIF may translocate from the mitochondria to nucleus in RCC tissues.

Association between AIF expression and clinicopathological features in patients with RCC. Positive AIF expression rate 
Table III. Association between AIF expression and clinicopathological data of patients with renal cell carcinoma.

\begin{tabular}{|c|c|c|c|c|}
\hline \multirow[b]{2}{*}{ Clinicopathological feature } & \multicolumn{2}{|c|}{ AIF expression } & \multirow[b]{2}{*}{$\chi^{2}$ value } & \multirow[b]{2}{*}{ P-value } \\
\hline & Positive, $\mathrm{n}$ & Negative, $\mathrm{n}$ & & \\
\hline \multicolumn{5}{|l|}{ Age, years } \\
\hline$<60$ & 10 & 24 & 6.157 & $0.013^{\mathrm{a}}$ \\
\hline$\geq 60$ & 6 & 56 & & \\
\hline \multicolumn{5}{|l|}{ Sex } \\
\hline Male & 10 & 53 & 0.083 & 0.773 \\
\hline Female & 6 & 27 & & \\
\hline \multicolumn{5}{|l|}{ T stage } \\
\hline $\mathrm{T} 1$ & 9 & 21 & 6.583 & $0.037^{\mathrm{a}}$ \\
\hline $\mathrm{T} 2$ & 3 & 39 & & \\
\hline T3 & 4 & 20 & & \\
\hline \multicolumn{5}{|l|}{ Grade } \\
\hline $\mathrm{I}$ & 10 & 26 & 6.400 & $0.041^{\mathrm{a}}$ \\
\hline II & 4 & 20 & & \\
\hline III & 2 & 34 & & \\
\hline \multicolumn{5}{|l|}{ Metastasis } \\
\hline With & 2 & 19 & 0.987 & 0.32 \\
\hline Without & 14 & 61 & & \\
\hline
\end{tabular}

${ }^{\mathrm{a}} \mathrm{P}<0.05$. AIF, apoptosis-inducing factor; $\mathrm{T}$, Tumor.
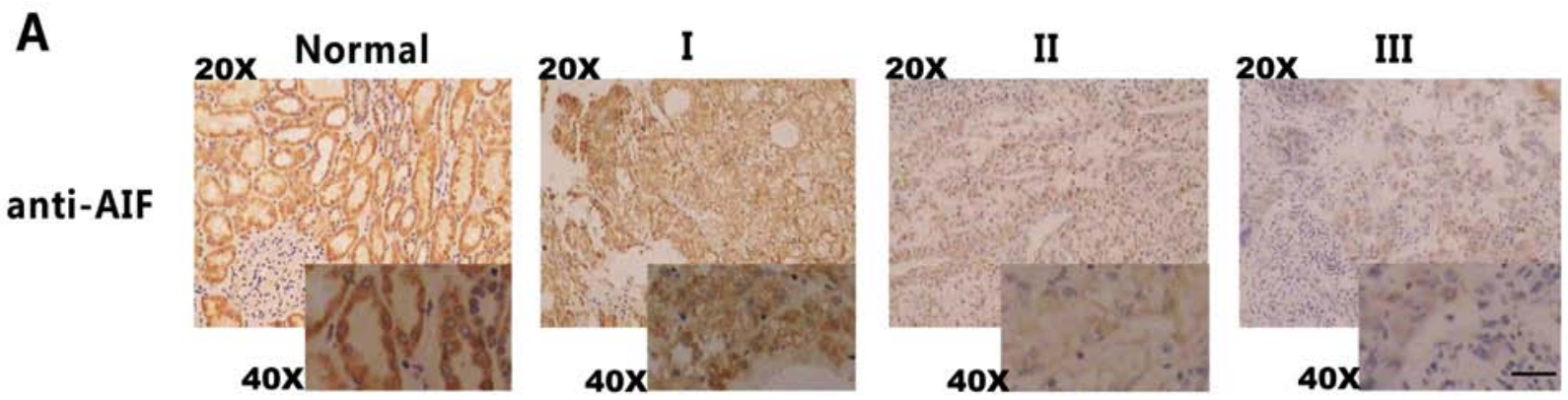

B

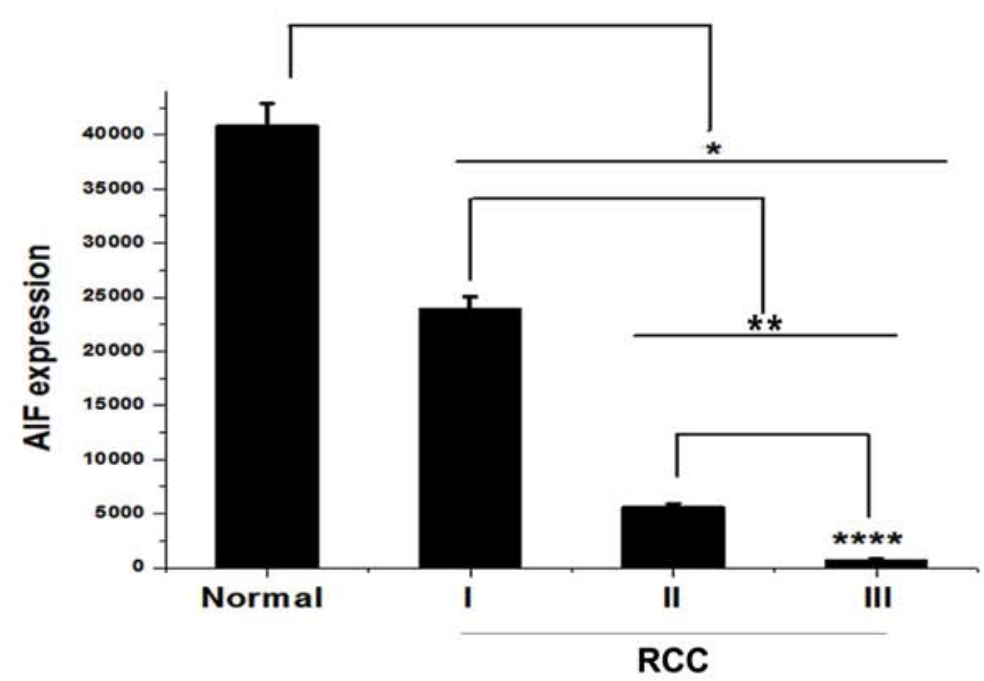

Figure 3. AIF expression in RCC grades I, II and III and adjacent normal tissue. (A) IHC staining of AIF (brown) revealed a decrease in AIF expression with tumor grade. (B) Quantification of AIF expression in RCC grades I, II and III. AIF expression was significantly decreased in RCC tissues compared with that in adjacent normal tissues. ${ }^{*} \mathrm{P}<0.05,{ }^{* *} \mathrm{P}<0.01,{ }^{* * * * *} \mathrm{P}<0.0001$. Scale bar, $400 \mu \mathrm{m}$. Normal, $\mathrm{n}=96$; grade $\mathrm{I}, \mathrm{n}=36$; grade II, $\mathrm{n}=24$; and grade II, $\mathrm{n}=36$ ). AIF, apoptosis-inducing factor; RCC, renal cell carcinoma. 
A

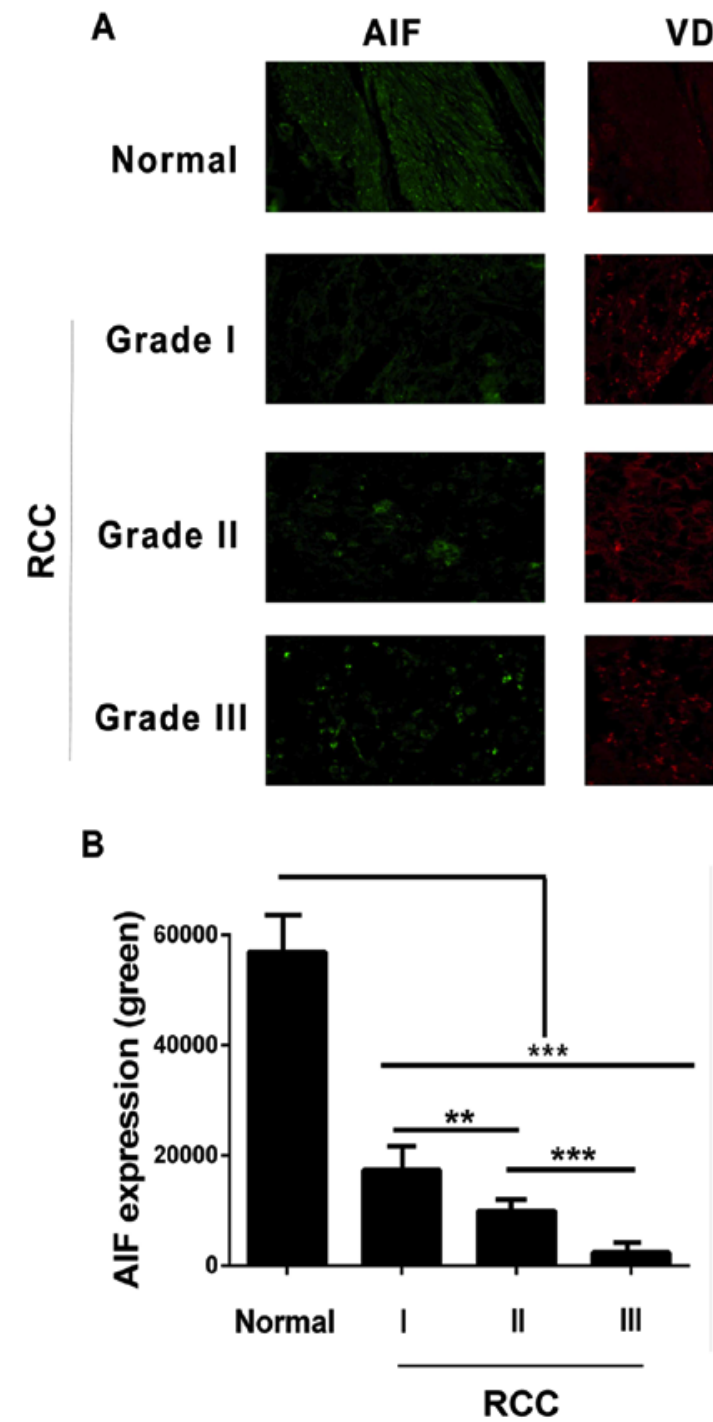

VDAC1

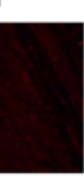

(2)
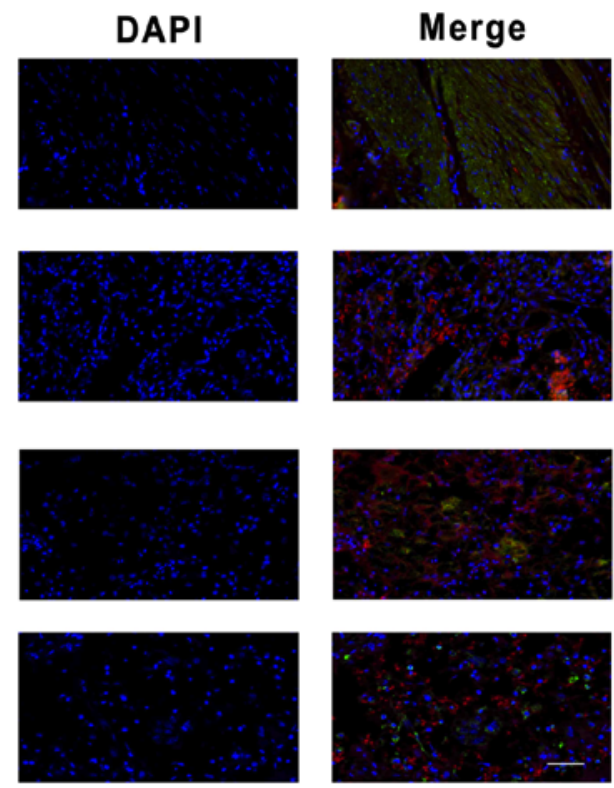

C

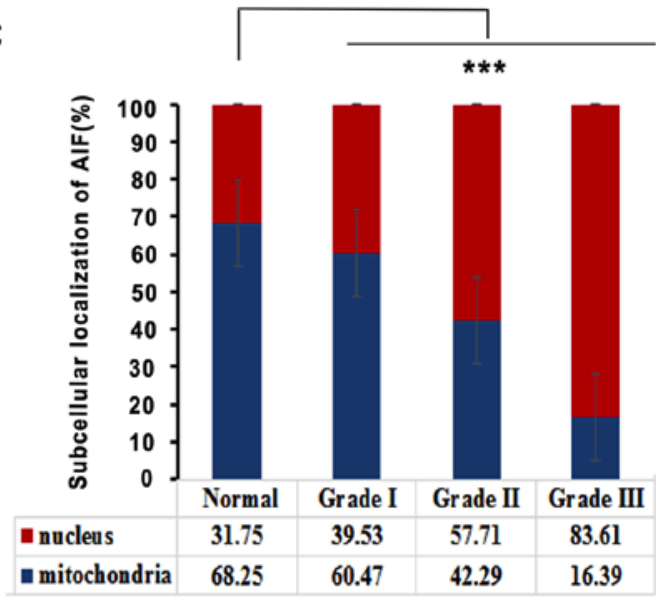

Figure 4. Subcellular localization of AIF in RCC cells. (A) Immunofluorescence staining of RCC grades I, II and III and adjacent normal tissue with antibodies against AIF (green), VDAC1 (red; mitochondrial marker) and with DAPI (blue; nuclear stain). (B) Quantification of AIF expression in RCC and adjacent normal tissue. (C) Quantification of AIF staining in mitochondrial and nuclear subcellular compartments in RCC grades I, II and III and adjacent normal tissue. ${ }^{* *} \mathrm{P}<0.01,{ }^{* * *} \mathrm{P}<0.001(\mathrm{n}=6)$. Scale bar, $500 \mu \mathrm{m}$. AIF, apoptosis-inducing factor; RCC, renal cell carcinoma; VDAC1, voltage-dependent anon-selective channel 1.

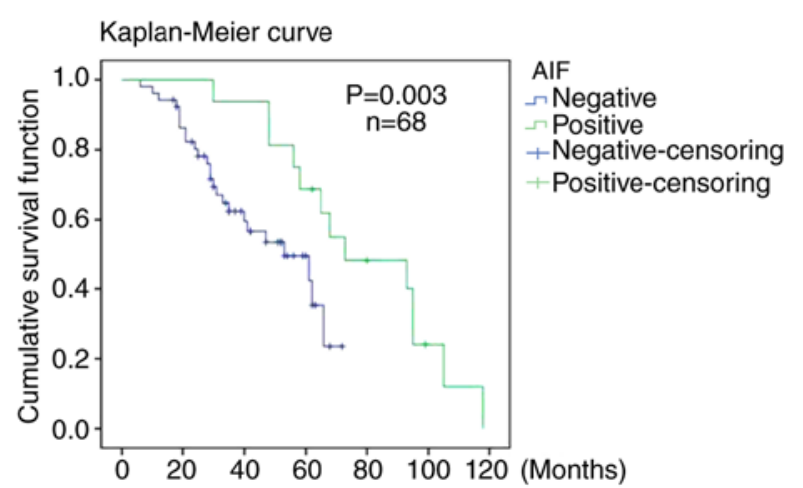

Figure 5. Postoperative survival rate of renal cell carcinoma patients with positive or negative AIF expression. Kaplan-Meier curves were used to analyze the postoperative survival rates. $\mathrm{P}=0.003(\mathrm{n}=68)$. AIF, apoptosis-inducing factor.

in $\mathrm{RCC}$ was associated with age, tumor (T) stage and grade $(\mathrm{P}<0.05$; Table III). The incidence of positive AIF expression in individuals aged $<60$ years was higher than that in individuals aged $\geq 60$ years. Based on clinical $T$ stage, the frequency of AIF-positive expression in stage T3 RCCs was significantly lower than that in stage T1 RCCs. Histopathological grade also indicated that the AIF-positive expression rate in patients with G3 grade RCCs was significantly lower than that in patients with G1 grade RCCs. These results suggest that decreased AIF expression is associated with RCC progression and grade. More severe malignancy was associated with decreased AIF-positive expression. AIF expression did not significantly differ between patients with lymph node metastasis and those without lymph node metastasis $(\mathrm{P}>0.05)$.

Negative AIF expression is associated with a worse survival rate. Of the 96 patients who underwent surgery, 68 were followed up for 6-118 months (mean follow-up time, 47 months). As presented in Fig. 5, the overall postoperative survival (OS) rate of the patients with negative AIF expression was significantly lower compared with that of patients with positive AIF 
expression $(\mathrm{P}=0.003)$. However, as the number of patients with positive AIF expression in the group was low, progression-free survival was not comparable between the two groups.

\section{Discussion}

AIF is thought to be a tumor suppressor and serves a critical role in caspase-independent cell apoptosis by triggering chromatin condensation and DNA fragmentation $(21,22)$. Following an apoptotic signal, AIF is translocated from mitochondria to the nucleus where it initiates caspase-independent programmed cell death $(3,23)$. However, AIF exhibits cell-type specificity in the induction of apoptosis. For example, in colon, breast and lung cancer cell lines, the mitochondria-to-nuclear localization of AIF was induced by peroxides and certain drugs used to treat cancer $(24,25)$. Of note, in several colon and squamous carcinomas, AIF expression was significantly upregulated $(26,27)$.

In the present study, 96 pairs of RCC and adjacent tissues were collected. Using IHC, it was demonstrated that AIF expression was significantly lower in RCC tissues compared with that in adjacent tissues. Although the IHC images in Fig. 3 appear notably different from the images in Fig. 1, this is due to the difference in the graphed background, and, as such, the quantification of AIF expression in Figs. 1B and 3B are very different due to the difference in staining color. In addition, immunofluorescent localization of the protein suggested that AIF translocated from mitochondria to the nucleus in RCC tissues (Fig. 4). AIF mRNA expression in RCC tissues, analyzed using RT-qPCR, was lower compared with that in normal renal tissues (Fig. 1). These results suggested that AIF downregulation in RCC tissue is associated with kidney tumorigenesis. Previous studies have reported that AIF was downregulated by factors such as hypoxia, microRNAs and epigenetic effectors (28-30). In addition, after 6-118 months of follow-up, the OS rates of patients with negative AIF expression were significantly worse compared with those of patients with positive AIF expression. Notably, a study by Xu et al (13) reported that AIF was significantly downregulated in kidney tumor specimens and that AIF overexpression induced apoptosis in RCC cells. The results of the present study are consistent with these findings reported by Xu et al (13).

In conclusion, $\mathrm{Xu}$ et al (13) suggested that AIF served a role in cell survival and kidney tumorigenesis, whilst the present study demonstrated an association between AIF expression and the progression of RCC. Therefore, AIF may serve as biomarker for RCC and determining AIF expression levels may have diagnostic value in patients with kidney tumors. Targeting AIF may be an effective treatment strategy for patients with RCC.

\section{Acknowledgements}

Not applicable.

\section{Funding}

This study was supported by the Hubei Polytechnic University School Talent Introduction Project (grant no. 180104), General project of Hainan Natural Science Foundation (grant no. 819MS136), Hubei Natural Science Foundation (grant no. 2014CFC1094), Huangshi Science and Technology Plan Project (grant no. 2014A069-1), Key Laboratory of Hubei Province 2014 Open Fund (grant no. SB201402) and Hubei Polytechnic University School Innovation Research Project (grant no. 14xjz05Q).

\section{Availability of data and materials}

All data generated or analyzed during the present study are included in this published article.

\section{Authors' contributions}

ZW designed and performed experiments. CY designed and performed experiments, analyzed data and drafted the manuscript. YH and ZL performed certain experiments. XY and $\mathrm{CL}$ analyzed the data, provided valuable assistance and critically revised the manuscript. ZS designed and supervised the project, assisted with data analysis and interpretation, and critically revised the manuscript.

\section{Ethics approval and consent to participate}

The present study was approved by the Ethics Committees of the Hubei Polytechnic University School (Huangshi, China) and that of the Haikou Hospital of Xiangya Medical School of Central South University (Haikou, China). Written informed consent was obtained from all patients.

\section{Patient consent for publication}

Written informed consent was obtained from all examined patients for the publication of their data.

\section{Competing interests}

The authors declare that they have no competing interests.

\section{References}

1. Ghezzi D, Sevrioukova I, Invernizzi F, Lamperti C, Mora M, D'Adamo P, Novara F, Zuffardi O, Uziel G and Zeviani M: Severe X-linked mitochondrial encephalomyopathy associated with a mutation in apoptosis inducing factor. Am J Hum Genet 86: 639-649, 2010

2. Susin SA, Lorenzo HK, Zamzami N, Marzo I, Snow BE, Brothers GM, Mangion J, Jacotot E, Costantini P, Loeffler M, et al: Molecular characterization of mitochondrial apoptosis-inducing factor. Nature 397: 441-446, 1999.

3. Joza N, Susin SA, Daugas E, Stanford WL, Cho SK, Li CY, Sasaki T, Elia AJ, Cheng HY, Ravagnan L, et al: Essential role of the mitochondrial apoptosis-inducing factor in programmed cell death. Nature 410: 549-554, 2001.

4. Green DR and Reed JC : Mitochondria and apoptosis. Science 281: 1309-1312, 1998.

5. Joza N, Pospisilik JA, Hangen E, Hanada T, Modjtahedi N, Penninger JM and Kroemer G: AIF: Not just an apoptosis-inducing factor. Ann N Y Acad Sci 1171: 2-11, 2009.

6. Shen SM, Guo M, Xiong Z, Yu Y, Zhao XY, Zhang FF and Chen GQ: AIF inhibits tumor metastasis by protecting PTEN from oxidation. EMBO Rep 16: 1563-1580, 2015.

7. Yu SW, Wang H, Poitras MF, Coombs C, Bowers WJ, Federoff HJ, Poirier GG, Dawson TM and Dawson VL: Mediation of Poly (ADP-ribose) polymerase-1-dependent cell death by apoptosis-inducing factor. Science 297: 259-263, 2002. 
8. Leslie NR, Yang X, Downes CP and Weijer CJ: PtdIns(3,4,5) $\mathrm{P}(3)$-dependent and independent roles for PTEN in the control of cell migration. Curr Biol 17: 115-125, 2007.

9. Yu CX, Li S and Whorton AR: Redox regulation of PTEN by S-nitrosothiols. Mol Pharmacol 68: 847-854, 2015.

10. Kim DH, Suh J, Surh YJ and Na HK: Regulation of the tumor suppressor PTEN by natural anticancer compounds. Ann N Y Acad Sci 1401: 136-149, 2017.

11. Tsai MJ, Chang WA, Tsai PH, Wu CY, Ho YW, Yen MC, Lin YS, Kuo PL and Hsu YL: Montelukast induces apoptosis-inducing factor-mediated cell death of lung cancer cells. Int J Mol Sci 18 E1353, 2017.

12. Ohyama M, Tsuchiya A, Kaku Y, Kanno T, Shimizu T, Tanaka A and Nishizaki T: Phosphatidylinositol derivatives induce gastric cancer cell apoptosis by accumulating AIF and AMID in the nucleus. Anticancer Res 35: 6563-6571, 2015.

13. Xu S, Wu H, Nie H, Yue L, Jiang H, Xiao S and Li Y: AIF downregulation and its interaction with STK3 in renal cell carcinoma. PLoS One 9: e100824, 2014.

14. Guo H, German P, Bai S, Barnes S, Guo W, Qi X, Lou H, Liang J, Jonasch E, Mills GB and Ding Z: The PI3K/AKT pathway and renal cell carcinoma. J Genet Genomics 42 343-353, 2015.

15. Kuusk T, Grivas N, de Bruijn R and Bex A: The current management of renal cell carcinoma. Minerva Med 108: 357-369, 2017.

16. Ye DW and Zhang HL: Critical appraisal of sorafenib in the treatment of Chinese patients with renal cell carcinoma. Onco Targets Ther 7: 925-935, 2014

17. Li XL, Chen XQ, Zhang MN, Chen N, Nie L, Xu M, Gong J, Shen PF, Su ZZ, Weng X, et al: SOX9 was involved in TKIs resistance in renal cell carcinoma via Raf/MEK/ERK signaling pathway. Int J Clin Exp Pathol 8: 3871-3881, 2015.

18. Heng DY, Xie W, Regan MM, Harshman LC, Bjarnason GA, Vaishampayan UN, Mackenzie M, Wood L, Donskov F, Tan $\mathrm{MH}$, et al: External validation and comparison with other models of the International metastatic renal-cell carcinoma database consortium prognostic model: A population-based study. Lancet Oncol 14: 141-148, 2013.

19. Li J, Huang JH, Qu QH, Xia Q, Wang DS, Jin L and Sheng C: Evaluating the microRNA-target gene regulatory network in renal cell carcinomas, identification for potential biomarkers and critical pathways. Int J Clin Exp Med 8: 7209-7219, 2015.

20. Bustin S and Nolan T: Talking the talk, but not walking the walk: RT-qPCR as a paradigm for the lack of reproducibility in molecular research. Eur J Clin Invest 47: 756-774, 2017.
21. Daugas E, Nochy D, Ravagnan L, Loeffler M, Susin SA, Zamzami N and Kroemer G: Apoptosis-inducing factor (AIF): A ubiquitous mitochondrial oxidoreductase involved in apoptosis. FEBS Lett 476: 118-123, 2000

22. Ohiro Y, Garkavtsev I, Kobayashi S, Sreekumar KR, Nantz R, Higashikubo BT, Duffy SL, Higashikubo R, Usheva A, Gius D, et al: A novel p53 inducible apoptogenic gene, PRG3, encodes a homologue of the apoptosis-inducing factor (AIF). FEBS Lett 524: 163-171, 2002.

23. Seth R, Yang C, Kaushal V, Shah SV, Kaushal GP. p53-dependent caspase-2 activation in mitochondrial release of apoptosis-inducing factor and its role in renal tubular epithelial cell injury. J Biol Chem 280: 31230-31239, 2005.

24. Agarwal E, Chaudhuri A, Leiphrakpam PD, Haferbier KL, Brattain MG and Chowdhury S: Akt inhibitor MK-2206 promotes anti-tumor activity and cell death by modulation of AIF and Ezrin in colorectal cancer. BMC Cancer 14: 145, 2014.

25. Yu JY, Zheng ZH, Son YO, Shi X, Jang YO and Lee JC: Mycotoxin zearalenone induces AIF- and ROS-mediated cell death through p53- and MAPK-dependent signaling pathways in RAW264.7 macrophages. Toxicol In Vitro 25: 1654-1663, 2011.

26. Jeong EG, Lee JW, Soung YH, Nam SW, Kim SH, Lee JY, Yoo NJ and Lee SH: Immunohistochemical and mutational analysis of apoptosis-inducing factor (AIF) in colorectal carcinomas. APMIS 114: 867-873, 2006.

27. Skyrlas A, Hantschke M, Passa V, Gaitanis G, Malamou-Mitsi V and Bassukas ID: Expression of apoptosis-inducing factor (AIF) in keratoacanthomas and squamous cell carcinomas of the skin. Exp Dermatol 20: 674-676, 2011.

28. Sun Y, Zhang Y, Wang X, Blomgren $\mathrm{K}$ and Zhu C: Apoptosis-inducing factor downregulation increased neuronal progenitor, but not stem cell, survival in the neonatal hippocampus after cerebral hypoxia-ischemia. Mol Neurodegener 7: 17, 2012.

29. Xiong Z, Guo M, Yu Y, Zhang FF, Ge MK, Chen GQ and Shen SM: Downregulation of AIF by HIF-1 contributes to hypoxia-induced epithelial-mesenchymal transition of colon cancer. Carcinogenesis 37: 1079-1088, 2016.

30. Xu H, Li J, Zhao Y and Liu D: TNFa-induced downregulation of microRNA-186 contributes to apoptosis in rat primary cardiomyocytes. Immunobiology 222: 778-784, 2017.

This work is licensed under a Creative Commons Attribution-NonCommercial-NoDerivatives 4.0 International (CC BY-NC-ND 4.0) License. 